\title{
EL CINE COMO PROPUESTA PEDAGÓGICA EN EL ALUMNADO DEL GRADO DE MAESTRO EN EDUCACIÓN PRIMARIA
}

\author{
Cinema as a Pedagogical Proposoal for Students of \\ Grade of Teacher in Primary Education
}

\author{
Miguel Jesús López Serrano \\ mjlopez@uco.es \\ Universidad de Córdoba. España \\ Fecha de recepción: 06/03/2019 \\ Fecha de aceptación: 01/07/2019
}

Resumen: El presente estudio analiza el desarrollo y el uso didáctico que tienen en la actualidad los recursos cinematográficos para los alumnos y alumnas del Grado de Magisterio de Educación Primaria en sus labores pedagógicas desde la perspectiva de futuros docentes. Creemos que un recurso educativo como el cine tiene un gran potencial para fomentar la cultura, el patrimonio cultural, así como una serie de valores cívicos y sociales. Es por ello que se han analizado una serie de variables cuyo objetivo es intentar comprender y dar respuestas a cuestiones que van desde la formación del profesorado en cinematografía, el uso de recursos audiovisuales en el aula, los equipamientos existentes, etc.

Los resultados obtenidos han evidenciado la buena aceptación por parte del alumnado universitario a la incorporación de este tipo de herramientas pedagógicas en las tareas educativas del aula a pesar, no obstante, de la escasa planificación y dotación de recursos que hay para optimizar esta práctica docente en la actualidad.

Palabras clave: Cine; Didáctica de las Ciencias Sociales; Educación primaria; Recursos Didácticos; Medios Audiovisuales.

Abstract: This study analyses the use of the cinema as an educational resource for the students of the Bachelor degree in Primary Education in their pedagogical training to be teachers. It is considered that an educational resource such as the cinema has great potential to promote culture, cultural heritage, as well as civic and social values. This is why a series of variables have been analyzed in order to understand and give answers to questions related to teacher training in cinematography, the use of audiovisual resources in the classroom, the existing equipments, etc. 
The obtained results have shown a good consideration by the university students about the incorporation of this type of pedagogical tools in the classroom. However, it' seems that nowadays there is already little planning and few resources to optimize this teaching practice.

Keywords: Cinema; Didactics Social Sciences; Primary Education; Educational Resources; Audiovisual Media.

SUMARIO: 1. Introducción. 2. El cine en el aula y los recursos audiovisuales. 3. Metodología y Objetivos. 4. Análisis y resultados de los datos obtenidos. 5. Conclusiones. 6. Bibliografía.

\section{INTRODUCCIÓN}

A la hora de abordar la cuestión del uso normalizado de materiales cinematográficos en la práctica educativa, tenemos que prestar especial atención al hecho de que son muchos los docentes que reivindican el poder contar no solo con unos recursos necesarios (aulas de cine, aparatos de proyección, base de datos de películas...) sino con unas dinámicas de trabajo y unas propuestas didácticas de garantías que puedan facilitar al profesorado la integración del cine en las clases escolares con un mínimo aprovechamiento pedagógico.

Desde que en los años 70 del siglo pasado se planteara por primera vez, desde una vertiente didáctica, el enseñar y aprender con ayuda del lenguaje audiovisual (Ambrós, 2011, pp. 8-9), han ido apareciendo diversas experiencias pedagógicas apoyadas, en mayor o menor medida, por las administraciones públicas que han tenido un impacto residual en el ámbito educativo consecuencia de dotarlas de una naturaleza extracurricular.

La escuela en la actualidad ha estado dejando en un segundo plano las bondades que el mundo cinematográfico pone a su disposición para enriquecer la labor educativa; sin aprovechar al máximo sus múltiples posibilidades como recurso didáctico en general.

Los profesionales de la educación no deben descartar ningún instrumento didáctico, deben saber aprovechar el uso de las imágenes como vehículo de transmisión de conocimientos y como puerta de entrada hacía otras disciplinas: pintura, escultura, arquitectura... si bien, no podemos obviar que gran parte del profesorado actual no está formado en competencias cinematográficas, no puede servir esto de excusa para alejar el cine de las aulas.

\section{EL CINE EN EL AULA Y LOS RECURSOS AUDIOVISUALES}

El lenguaje de las imágenes tiene la cualidad de mostrarnos una libertad para enseñarnos cualquier aspecto de la sociedad actual, pasada y futura; igualmente, puede sustentarse en hechos reales o ficticios a la hora de presentar ciertos 
acontecimientos temáticos curriculares por lo que las posibilidades didácticas que ofrece al alumnado son muy amplias:

- El cine fomenta la reflexión, la sensibilización y el espíritu crítico ante problemas vitales.

- Es un elemento dinamizador y motivador del aula que enriquece la labor de enseñanza-aprendizaje.

- Se puede fomentar el estudio y uso de cualquier competencia que establezca la legislación vigente. En nuestro caso particular cobra especial relevancia la social y cívica.

- El séptimo arte puede ser un catalizador lúdico de la lectura en el aula.

- Las imágenes sobre el tiempo histórico representado en las películas son el mejor ejemplo para evaluar aspectos sociales, vestimentas, paisajes, gestualidad...

Entendemos, pues, como el cine es una herramienta educativa que destaca sobremanera por la capacidad de enseñar desde una metodología lúdica y relajada para el alumnado. Bellido López (1998) afirma: «El cine se puede enseñar de muchas formas y se puede conseguir que el alumnado desde cualquier edad pueda amarlo. Esa es una de nuestras ideas: llegar a comprender, de esa forma, el maravilloso lenguaje de las imágenes». A su vez, posibilitan el desarrollo del currículum de Primaria al entroncar temas tanto de índole social como del medio natural por lo que abre un abanico de posibilidades metodológicas y de recursos para el aprendizaje de contenidos de las Ciencias Experimentales y Sociales ${ }^{1}$.

Permitir que alumnado conozca uno de los lenguajes audiovisuales en las que la interacción de los códigos verbales y no verbales es más rica y eficaz para la transmisión de significados y la construcción de los imaginarios personajes. Facilitar un medio para el conocimiento y la expresión que beneficia el desarrollo de las capacidades creativas, cognoscitivas, artísticas y expresivas... Propiciar un instrumento para la creación a partir de los conocimientos y experiencias propias. (Martínez Salanova y Pérez, 2002, p. 77).

A pesar de las bondades anteriormente expuestas, el cine, creemos, se encuentra en la actualidad bastante desaprovechado en los centros educativos. Un amplio sector de la comunidad docente no encuentra o no sabe encontrar en los filmes una herramienta eficaz y válida para introducirla en el aula, este hecho puede ser consecuencia de diversos factores, entre los que destacamos la mínima planificación metodológica que haga un uso funcional del cine, de selección filmográfica según los patrones de edad del alumnado, creación de propuestas didácticas que inserten los contenidos curriculares, disponer de los medios tecnológicos necesarios y, lo más importante según

${ }^{1}$ Para ampliar la información sobre las posibilidades metodológicas del cine, véase Torre et al., 2003-2004. 
nuestro parecer, tiempo para la realización completa de las actividades desde una perspectiva contextualizada, haciendo hincapié en su utilidad y no simplemente como un mero entretenimiento, por lo que, no es de extrañar, que muchos profesores hagan uso del cine para ocupar horas sueltas o para rellenar cualquier tipo de imprevistos (periodos vacacionales, ausencia de profesorado, semanas culturales...).

La implantación sine die de las herramientas TIC choca de plano con una idea prefijada en la mente de muchos discentes, los cuales creen que en la enseñanza debe primar por encima de todo las palabras y no las imágenes. Plataformas como YouTube, Vimeo, etc.; proyectos como CINEscola, programas de innovación educativa... han facilitado, en gran medida, la incorporación en las programaciones didácticas de películas, documentales, etc. como herramientas educativas. Hoy día, los repositorios filmográficos tanto gratuitos como de pago que podemos encontrar en internet y de los que pueden hacer uso los docentes son prácticamente inagotables. Es, por tanto, la profesionalidad del maestro la que dictamine si se hace un buen uso (planificado, contextualizado, temporalizado...) o se queda, simplemente, en la improvisación o el relleno con esos fragmentos de películas o cualquier material fílmico que podemos encontrar en dichas plataformas.

El alumnado de primaria, ESO y sobre todo de Bachillerato, empieza a elaborar sus primeros juicios críticos con toda la información que las imágenes ponen a su disposición, con ello, empiezan a formar sus propios conjuntos de valores, códigos éticos y morales; elementos preponderantes en el desarrollo cognitivo de la persona, por lo que el aula no puede ser ajena a esta realidad debiendo incorporar cuanto antes el cine en la cotidianidad educativa presente.

La enseñanza a través del cine nos ofrece una beneficiosa cualidad que difiere de otras muchas disciplinas como consecuencia de que la imagen está presente como un elemento normalizado en el desarrollo de la persona desde sus primeros años de vida en todos sus ámbitos (Fernández Ulloa, 2012, p. 1). Desde el punto de vista teórico el docente, a la hora de seleccionar el material audiovisual, debe realizar una valoración sistemática de los conocimientos, requisito previo antes de cualquier acción didáctica. Pérez Parejo (2010, p. 3) en su intervención en el // Congrés Internacional de DIDACTIQUES sostiene que:

- Etapa de Infantil: Se deben seleccionar videos didácticos sobre el entorno más cercano de los menores, tanto urbanos como rurales, fenómenos meteorológicos, naturaleza, biodiversidad y videos que fomenten la higiene personal y la limpieza en general, entre otros.

- Educación Primaria: Elección de una temática más compleja, como por ejemplo conocimiento de otras culturas, presentación de distintas épocas históricas, elementos del patrimonio históricos, documentales biográficos, películas en versión original...

- Para Secundaria: La Enseña Secundaria Obligatoria es la etapa ideal para introducir al alumnado la educación en valores y la ética. Podemos seleccionar gran cantidad 
de filmes que reflejen distintos aspectos de la realidad como la perspectiva de género, el fracaso escolar, bullying, igualdad de género, la pobreza; sin dejar de lado la recreación de distintos periodos históricos, cine de autor...

Una vez decididos a seguir los postulados del ínclito historiador francés Lucien Febvre (1976), integrante de la escuela de los Annales, el cual defendía el derecho de transgredir el honor de los documentos archivísticos como las únicas fuentes para el conocimiento de nuestro pasado histórico, con la utilización de fuentes de diversa naturaleza, entre las cuales y, en nuestro caso particular, el cine se encontraría en los primeros lugares.

Así pues, a la hora de utilizar los documentos fílmicos como recurso educativo para el estudio de las Ciencias Sociales y Experimentales, podemos acudir a la clasificación que nos plantea el profesor Valle Aparicio (2007, pp. 449-450) para el aprendizaje de la didáctica histórica:

1. Cine cuya temática refleje y presente distintas culturas, sociedades, modos de vida.

2. Películas que alberguen un alto contenido analítico y crítico para analizar una etapa histórica concreta, una cultura pasada...

3. Por último, aquella filmografía que englobe los aparatados anteriores.

\section{METOdOLOGÍA Y OBJETIVOS}

A la hora de abordar un estudio de estas características, con todas las limitaciones que conlleva, hemos creído conveniente seleccionar una muestra relativa de un grupo de alumnos y alumnas de la asignatura Didáctica de las Ciencias Sociales en Educación Primaria, del grado de Maestro en Educación Primaria, de la Universidad Internacional de La Rioja (UNIR). En total se realizó la encuesta a 86 alumnos y alumnas, con un predominio del género femenino 54 mujeres $(62,8 \%)$ frente a los 32 hombres $(37,2 \%)$ del total de la muestra.

En estas líneas se esbozará brevemente una pequeña investigación sociocrítica sobre la utilización de materiales cinematográficos como un recurso para la enseñanza y aprendizaje en la Educación Primaria. Para ello, hemos definido dos objetivos temáticos principales:

1. Diagnosticar los conocimientos previos que atesoran alumnos y alumnas del grado de Maestro en Educación Primaria (futuros docentes) sobre el uso del cine en el aula como herramienta pedagógica.

2. Presentar una serie de propuestas o alternativas de mejora, al hilo de los resultados obtenidos, que puedan beneficiar su utilización desde un punto de vista integrador del proceso docente. 
Hemos decidido hacer uso de una metodología mixta que incluye un análisis cualitativo y cuantitativo de los datos mediante un cuestionario compuesto de preguntas de carácter abierto y cerrado.

- Etapa 1.․ En esta fase inicial realizaremos una pequeña cata bibliográfica. Delimitaremos el alcance del objeto de estudio y seleccionaremos la asignatura y el alumnado más propicio para llevarlo a cabo.

- Etapa 2.a. Elección y elaboración de las preguntas que conformarán el cuestionario.

- Etapa 3.a. Recogida de los datos obtenidos de las diez cuestiones planteadas a los 86 participantes de la investigación. Se incluye el análisis de las respuestas con un enfoque metodológico mixto entre lo cualitativo y cuantitativo.

- Etapa final. En esta última fase se plantearán una serie de conclusiones.

\section{ANÁLISIS Y RESULTADOS DE LOS DATOS OBTENIDOS}

Para la realización de la investigación se seleccionaron un número de 10 variables con respuestas en su mayoría abiertas. Estos ítems fueron elegidos siguiendo una similitud temática. Las cuestiones presentadas al alumnado fueron las siguientes:

\section{VARIABLES ANALIZADAS}

1 ¿Crees que un recurso didáctico como el cine debería ser utilizado en el aula de manera normalizada?

2 ¿El cine sería una buena herramienta para fomentar el desarrollo de habilidades y capacidades (expresión oral, sensibilidad, capacidad creativa...) planteadas en el currículum de Primaria?

3 ¿Existe un equipamiento adecuado en tu aula para la reproducción de materiales audiovisuales?

4 ¿Está el profesorado de Educación Primaria convenientemente formado en el uso docente de recursos audiovisuales?

5 ¿Cuáles son las asignaturas o áreas que más se adecuarían al uso del cine?

$6 \quad$ ¿El visionado de películas puede reforzar la identificación personal de los alumnos con los valores y actitudes trabajados? (Sí o No.)

7 ¿Existe una buena adecuación del tiempo (clases) necesario para realizar la práctica educativa con el cine?

8 ¿Es el cine un recurso riguroso y fiable para la enseñanza de conocimientos?

9 ¿Cuál fue la última película de temática histórica que has visto? ¿Conoces las siguientes películas?

10 ¿Es necesario que el alumnado posea una serie de conocimientos previos sobre cine para obtener un máximo beneficio educativo? 
Tras analizar los datos recogidos, podemos observar que en la pregunta número 1, como esperábamos, una amplia mayoría $89,3 \%$ se muestra claramente a favor de utilizar de manera estandarizada el cine como una posibilidad más dentro del abanico de recursos didácticos que tiene el docente a la hora de plantear las tareas de enseñanza-aprendizaje. Solo un 6,1 \% de los encuestados se expresaron partidarios de no utilizar el cine como herramienta pedagógica en la educación primaria, mientras que el $4,6 \%$ no saben o no contestan.

Según los datos obtenidos sobre la conveniencia del uso del cine para fomentar las habilidades y capacidades planteadas en el currículum de primaria, las respuestas han sido en su mayoría positivas, no obstante, no estamos del todo seguros del grado de conocimiento del alumnado del marco legal, por lo que podemos considerar este ítem como una variable orientativa de la opinión global sobre el asunto abordado. Los índices de porcentaje reflejaron: es una buena herramienta $(82,1 \%)$, no le parece adecuado su uso $(3,4 \%)$, no sabe o no contesta $(14,5 \%)$.

Figura 1

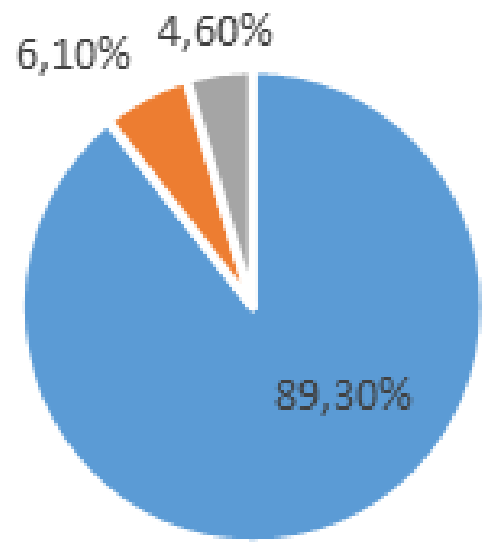

Fuente: Elaboración propia

La siguiente pregunta efectuada está destinada a indagar sobre los recursos materiales con los que cuenta el docente para llevar a cabo las labores pedagógicas audiovisuales y con qué tipo de dotación para analizar el equipamiento existente en el centro ${ }^{2}$. Una vez concluida la revisión de los datos el alumnado respondió

2 Debemos señalar que la Universidad Internacional de La Rioja (UNIR) es un centro educativo online. Hicimos hincapié a los estudiantes que respondieran en base a las Instituciones en las que realizaron sus prácticas $u$ otros de los que formaron parte años anteriores. 
que existe una manifiesta preeminencia del ordenador (94\%) con respecto a otro medio de reproducción. En segunda posición encontramos la televisión (83,5 \%), seguida del proyector $(81,5 \%)$. Inmediatamente con una menor presencia y, en casos casi residuales, nos encontramos el reproductor de DVD (24,8 \%), Radio Cd $(8,1 \%)$, reproductor de diapositivas $(1,4 \%)$. Debemos reseñar que en algunos cuestionarios se denota cierto desconocimiento por parte del alumnado de los recursos existentes en su centro de estudio al responder: los desconozco. Algunos medios reseñados como prensa escrita, reproductores VHS o cámaras de video, arrojaron porcentajes mínimos que no creemos de importancia detallarlos.

Tabla 1. Equipamiento y Frecuencia de uso

\begin{tabular}{ccccccccc} 
& Ordenador & TV & Proyector & R. DVD & $\begin{array}{c}\text { Radio } \\
\text { Cd }\end{array}$ & $\begin{array}{c}\text { R. } \\
\text { Diapositivas }\end{array}$ & Otros \\
& 84 & 72 & 70 & 21 & 7 & 2 & 1 & Número \\
& 94 & 83,7 & 81,3 & 24,4 & 8,1 & 2,3 & 1,1 & Porcentajes \\
\hline $\begin{array}{c}\text { Diario } \\
\text { Con } \\
\text { frecuencia } \\
\text { Alguna vez }\end{array}$ & 96 & & & & & & & Uso (\%) \\
Nunca & & 36.5 & & & & & & \\
\hline
\end{tabular}

Fuente: Elaboración propia.

Podemos destacar al hilo de los resultados que los alumnos y alumnas que han colaborado en el estudio son usuarios casi en exclusiva del ordenador con una frecuencia de uso diaria. De los restantes medios audiovisuales no se declaran usuarios frecuentes ni se encuentran habituados a su funcionamiento. Un porcentaje del 7,6 \% han respondido que hacen uso de la prensa alguna vez.

En referencia a la pregunta sobre la preparación en cine del profesorado de Educación Primaria, el 79 \% de los participantes han mostrado su interés en que los docentes puedan acceder a una formación específica sobre la cuestión, siendo la forma preferida mediante unas jornadas o cursos impartidos en el propio centro académico donde se desarrolle la labor educativa. Por otro lado, un $12 \%$ no creen que los profesores en la actualidad tengan las competencias básicas adquiridas para un uso óptimo de los medios audiovisuales en el aula. Frente a ambas posiciones un $9 \%$ respondieron que no podían o no sabían evaluar el grado de formación del profesorado.

La siguiente cuestión está planteada para ser respondida de manera abierta. Se preguntaba qué tipo de materias serían las más adecuadas para trabajar con el cine en clase como una herramienta pedagógica más. Lógicamente las disciplinas que más presencia tuvieron en el cuestionario fueron las relacionadas con el ámbito de las ciencias sociales y las humanidades. 
Tabla 2. Asignaturas idóneas para el uso del cine en clase

\begin{tabular}{cccccccccc}
\multicolumn{2}{c}{ Ciencias Sociales } & \multicolumn{2}{c}{ Historia } & \multicolumn{2}{c}{ Inglés } & \multicolumn{2}{c}{ C Naturaleza } & \multicolumn{2}{c}{ Religión } \\
\hline N.․ & $\%$ & N.. & $\%$ & N.o & $\%$ & N.o & $\%$ & N.o & $\%$ \\
78 & 90,6 & 72 & 83,7 & 45 & 52,3 & 39 & 45,3 & 4 & 4,6 \\
\hline \multicolumn{8}{c}{ Fuente: Elaboración propia. }
\end{tabular}

En correspondencia con los datos obtenidos en la pregunta sobre la identificación con valores y actitudes tratados, el alto porcentaje anotado en las respuestas nos sirve para intentar responder a una de las hipótesis que habíamos planteado con esta investigación. Se confirma pues la importancia del cine como recurso y su necesidad de implementarlo en las rutinas de las clases y en las prácticas docentes, igualmente podemos apuntar que no hemos notado ninguna diferencia reseñable en relación a las variables de género; tanto hombres como mujeres creen, en rotunda mayoría $(96,6 \%)$ que el cine puede ayudar en las tareas de enseñanza-aprendizaje en tanto en cuanto es una fuente viva de inagotable información y cultura que permite valorar el estudios de diferentes parcelas de la realidad social y personal; en palabras de (Salanova Sánchez, 2016, p. 87):

Consideramos, por tanto, que es de relativa facilidad su utilización como elemento transversal del aprendizaje, además de que nos parece que su uso facilita el desarrollo de las capacidades de comunicación, pensamiento lógico y conocimiento del entorno social y natural del alumnado, que son las finalidades que se pretenden en la Educación Primaria.

En la pregunta número 7, respecto a si existe una buena planificación horaria para el uso del cine, comprobamos que un elevado porcentaje de estudiantes tiene la percepción de que, por diversos motivos, el tiempo destinado para la realización de actividades con recursos audiovisuales no es proporcional a la importancia del mismo. Un $78 \%$ aduce la falta de equipamiento y tiempo para planificar el trabajo en la clase, mientras, un $62,7 \%$ cree que el impedimento radica en la poca flexibilidad del horario escolar; por último, el $43,5 \%$ imanta esta poca disponibilidad horaria a la falta de motivación del profesorado.

Revisados los datos de la pregunta relativa a la rigurosidad y fiabilidad del cine como fuente de contenidos para la educación primaria podemos indicar como la mayoría del alumnado encuestado tiene una percepción positiva sobre la cuestión abordada, a pesar, como hemos indicado anteriormente, de que los recursos cinematográficos no se encuentran entre los más utilizados en la práctica educativa ni gozan de gran aceptación como fuentes de contenidos en gran parte de la comunidad educativa; en correlación hemos comentado en líneas anteriores que el uso mayoritario del cine en el aula se circunscribe a las 
disciplinas sociales o a las humanidades, exceptuando las Ciencias de la Naturaleza. Así pues, por lo que respecta a los resultados obtenidos, el 77,3 \% de los encuestados creen que efectivamente los materiales audiovisuales son unos recursos tan fiables y válidos como las monografías, publicaciones periódicas, etc. El punto de vista contrario es secundado por el $14,7 \%$ y solo el $8 \%$ declararon que NS/NC.

Si uno de los principios básicos con más fuerza en la actualidad es la vinculación entre comunidad educativa y sociedad, la escuela no puede mantenerse ajena a esta realidad, es más, debe acortar distancias entre la vida de los escolares y el sistema educativo. Para eso, el cine no sólo ha de estar presente en la escuela, sino que además demanda conocimientos en continua actualización para su adecuada comprensión y utilización. Esto significa no considerarlo como un parche alternativo dentro del proceso de enseñanza-aprendizaje del alumnado, sino como una porción integrante de todo el currículo. (Pereira Domínguez y Marín Valle Sánchez, 2001, p. 235).

Una vez expuestos los resultados sobre el uso del cine como fuente de inestimable rigor, se les propuso a los alumnos y alumnas que realizaran un ejercicio de memoria para comprobar el grado que tenían de conocimientos mínimos sobre cinematografía; más concretamente sobre filmografía. Para ello se les proporcionó un listado de 50 películas con un marcado carácter académico para que señalaran las que habían visto o que, al menos, conocieran. El 52,6 \% eran desconocidas o no habían sido visionadas, mientras que los 18 filmes restantes (47,3\%) sí formaban parte de la filmografía de los encuestados. En este primer análisis, los datos reflejan el escaso nivel de cultura cinematográfica de los futuros docentes de educación primaria al desconocer la mayoría de las películas listadas. Creemos, por tanto, que se hace necesario demandar una formación básica en el futuro profesorado para la comprensión y puesta en práctica de los recursos audiovisuales ${ }^{3}$.

${ }^{3}$ En referencia a qué organismo sería el encargado de realizar esa formación, destaca la encuesta realizada por las profesoras Pereira Domínguez y Marín Valle Sánchez (2001): «[...] un $50,5 \%$ se inclinan por los centros de formación de profesores y recursos: un $23,4 \%$ señalan el centro educativo donde trabajan; un $15,8 \%$ citan a la universidad, y finalmente, un $10,3 \%$ apuntan que es una función independiente y particular de cada docente» (p. 250). 
Tabla 3. Listado de películas de posible uso académico

Propuesta de filmes como recurso pedagógico

\begin{tabular}{|c|c|c|c|}
\hline Amadeus & 凶 & Jasón y los argonautas & $\square$ \\
\hline American History $\mathrm{X}$ & 区 & La clase & $\square$ \\
\hline Anastasia & $凶$ & La educación prohibida & $\square$ \\
\hline Atrapa la bandera & $\square$ & La guerra de Troya & 凶 \\
\hline Babe, el cerdito valiente & 凶 & La Marsellesa & $\square$ \\
\hline Billy Elliot & 凶 & La ola & 区 \\
\hline Buda explotó por vergüenza & $\square$ & La ruta hacia el dorado & 区 \\
\hline Cadena de favores & 区 & Las aventuras del pequeño Colón & 区 \\
\hline Cobardes (bullying) & $\square$ & Lisístrata & $\square$ \\
\hline Edipo Rey & $\square$ & Los chicos del coro & 凶 \\
\hline Eduardo Manostijeras & 凶 & Los mejores años de nuestra vida & $\square$ \\
\hline El abuelo & $\square$ & Medea & $\square$ \\
\hline El espinazo del diablo & $\square$ & Monsieur Batignole & $\square$ \\
\hline El Gatopardo & $\square$ & Octubre & $\square$ \\
\hline El gran dictador & 区 & Pena de muerte & 凶 \\
\hline El nombre de la rosa & $\bigotimes$ & Robin Hood & 区 \\
\hline El tercer hombre & $\square$ & Salvar al soldado Ryan & 区 \\
\hline En tierra de nadie & 凶 & Ser y tener & $\square$ \\
\hline Entre maestros & $\square$ & Severo Ochoa, la conquista de un Nobel & $\square$ \\
\hline Estrellas en la tierra & $\square$ & Soldados de Salamina & 凶 \\
\hline Furia de Titanes & 凶 & Sufragistas & $\square$ \\
\hline Gandhi & 凶 & ¿Teléfono rojo? & $\square$ \\
\hline Gladiator & 凶 & Una bolsa de canicas & $\square$ \\
\hline Gru, mi villano favorito & 凶 & UP & 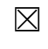 \\
\hline Historia de una gaviota & $\square$ & ¡Viva Zapata! & $\square$ \\
\hline
\end{tabular}

Fuente: Elaboración propia. 
La última pregunta planteada versaba sobre la conveniencia de que el alumnado del Grado de Maestro de Educación Primaria tuviera unos conocimientos previos básicos sobre cultura cinematográfica. Partimos de la premisa que el alumno y alumna son personas que tienen que estar en permanente formación al igual que intrínsecamente motivados. De las respuestas obtenidas destacamos que el 70,8\% se muestran partidarios de poseer una serie de contenidos mínimos en contraposición del 22,3\% que no creen necesario el disponer de una cultura básica sobre filmografía pedagógica. El restante 6,9\% NS/NC.

Ante el interés mostrado por obtener una formación específica debemos ir descartando la idea que subyace en el imaginario colectivo académico de que la utilización del cine se realiza para rellenar huecos de horas sobrantes, el impedimento acuciante de la falta de equipamiento y recursos o una mala planificación en la programación de las asignaturas (Fernández Ulloa, 2012). La falta de entendimiento entre la práctica y la potencialidad de estos recursos debe ser revertida a través de una buena formación del alumnado, desde las primeras etapas de la educación hasta su llegada a la función profesional. El sistema educativo no puede ni debe estar ajeno a una realidad social imperante como es la información audiovisual, no debe excluirla de las tareas de enseñanza-aprendizaje.

\section{CONCLUSIONES}

Esta investigación ha intentado conocer de primera mano las opiniones e intereses de un grupo de estudiantes del grado de magisterio en Educación Primaria, docentes en ciernes y protagonistas de la realidad pedagógica de nuestro futuro más cercano.

Destaca, en primer lugar, la necesidad de una respuesta que englobe a las instituciones educativas, los responsables políticos, los docentes y, en general, la sociedad en su conjunto para intentar fomentar una buena praxis educativa con el cine como protagonista. Se precisa de una sensibilización y responsabilidad del profesorado a la hora de planificar unas acciones educativas completas, que se integren en el currículum, programaciones, unidades didácticas... de manera estandarizada y no solo que quede su uso reducido a horas sueltas o de nula utilidad teórico-práctica. Igualmente, es una responsabilidad y una obligación que las autoridades académicas doten de unas mínimas infraestructuras, de unos materiales pedagógicos adecuados para fomentar el uso de los recursos cinematográficos en el aula con calidad para propiciar un espacio motivacional óptimo por parte de los profesionales de la educación.

Asimismo, al hilo de los datos obtenidos, hemos detectado una disonancia entre las posibilidades académicas y el uso real que tiene el cine como contenido para desarrollar una asignatura para la etapa de primaria. A pesar de la buena 
aceptación que tienen los medios audiovisuales como recursos que tienen la capacidad de transmitir conocimientos de una manera lúdica entre el alumnado en formación (Vega, 2002), su utilización prácticamente queda reducida al uso del ordenador. La justificación expuesta es el desconocimiento, en muchos casos, del equipamiento audiovisual, más allá del PC. Estos datos denotan la escasa utilización de las herramientas audiovisuales por parte de los docentes en la etapa formativa de los encuestados y el poco bagaje formativo con el que llegan al grado la próxima generación de profesores.

Creemos, igualmente, que un elemento que no enriquece la acción educativa de la cinematografía en la escuela radica en que una muestra considerable de las películas elegidas en el estudio son prácticamente desconocidas para el grupo de alumnos y alumnas participantes, así como por una gran parte de los docentes, siendo las más reconocidas las que fueron grandes éxitos comerciales como: $L a$ guerra de Troya (Wolfgang Petersen, 2004), Soldados de Salamina (David Trueba, 2003), Gladiator (Ridley Scott, 2000), Gandhi (Richard Attenborough, 1982), Eduardo Manostijeras (Tim Burton, 1990), Salvar al soldado Ryan (Steven Spielberg, 1998), Robin Hood (Kevin Reynolds, 1991).

Debemos interpelar una vez más al esfuerzo conjunto para conseguir optimizar la tarea enseñanza-aprendizaje a través del cine para conseguir no ahondar en la brecha digital entre el alumnado y profesorado; la escuela debe adaptarse a la sociedad (digital y virtual) en la que se inserta y no llegar siempre tarde (Marcos Ramos, 2010); las generaciones experimentan constates cambios en su evolución y es una preocupación de las autoridades educativas el adaptar la realidad social del alumnado con unos contenidos audiovisuales que eduquen en y con el cine.

\section{BIBLIOGRAFÍA}

Ambrós, A. y Breu, R. (2007). Cine y educación. El cine en el aula de primaria y secundaria. Barcelona: Graó.

Bellido López, A. (1998). El aprendizaje del cine. Comunicar, 11, pp. 13-20.

Benet Ferrando, V. J. (2001). El cine en la enseñanza de la historia. Aula historia social, 8.

Bermúdez Briñez, N. (2008). El cine y el video: recursos didácticos para el estudio y la enseñanza de la historia. Revista de Teoría y Didáctica de las Ciencias Sociales, 13. 
Breu, R. (2012). La historia a través del cine. 10 propuestas didácticas para secundaria y bachillerato. Barcelona: Graó.

Faulstich, W. y Korte, H. (1997). Cien años de cine. Desde los orígenes hasta su establecimiento como medio. Madrid: Siglo veintiuno editores.

Fernández Ulloa, T. (2012). La importancia del uso del cine como medio educativo para niños. Editorial Ocendi.

García Córdoba, F. (2002). El cuestionario. Recomendaciones metodológicas para el diseño de cuestionarios. Madrid: Limusa.

Gómez Galán, J. (2000). Tecnologías de la información y la comunicación en el aula: Cine y radio. Madrid: Seamer.

Loscertales, F. y Núñez, T. (2001). Comunicación y habilidades sociales para la intervención en grupos: comunicación e intervención. Sevilla: Universidad de Sevilla.

Marcos Ramos, M. (2010). Alfabetización mediática. La educación en los medios de comunicación: cine formativo y televisión educativa. Teoría de la Educación. Educación y Cultura en la Sociedad de la Información, 11, pp. 303-321.

Martínez-Salanova Sánchez, E. (1997). El valor de la imagen en movimiento. Comunicar, 9, pp. 23-35.

Martínez-Salanova Sánchez, E. (1998). Aprender pasándolo de película. Comunicar, 11, pp. 27-36.

Martínez-Salanova Sánchez, E. (2003). El valor del cine para aprender y enseñar. Comunicar, 20, pp. 45-52.

Méndez, J. M. (2001). Aprendemos a consumir mensajes. Televisión, publicidad, prensa y radio. Huelva: Grupo Comunicar Ediciones.

Monterde, J. E. (1986). Cine, historia y enseñanza. Barcelona: Laia.

Nadal Martín, M.a A. (1991). Los medios audiovisuales al servicio del centro educativo. Madrid: Castalia. 
Pablos Pons, J. de. (1986). Cine y enseñanza. Variables estructurales del Cine Didáctico y su interacción con algunas características de los alumnos. Madrid: Centro de Publicaciones del Ministerio de Educación y Ciencia.

Prats, LI. (2007). Cine para educar. Barcelona: Belacqua.

Rodari, G. (2006). Gramática de la fantasía: Introducción al arte de contar historias. Barcelona: Booket.

Romaguera, J. et al. (1989). El cine en la escuela. Elementos para una didáctica. Barcelona: Gustavo Gili.

Torre, S. de la et al. (2003-2004). El cine como estrategia didáctica innovadora. Metodología de estudio de casos y perfil de estrategias docentes. Contextos educativos, 6-7, pp. 65-86.

Valle Aparicio, E. (2007). Cine e historia: sobre la utilización de los documentos soporte video en la enseñanza de la historia. Actas del I Congreso Internacional de lengua, Literatura y Cultura Española: La Didáctica de la enseñanza para extranjeros (pp. 445-458). JMC.

Vega, A. (2002). Cine, drogas y salud: recursos para la acción educativa. Comunicar, 18, pp. 123-129. 